\title{
HR Managers' Views on SHRM and Its Role in Influencing Organizational Performance
}

\author{
Mariam Bassem \\ German University in Cairo \\ Cairo, Egypt \\ E-mail: mariambassem9591@gmail.com \\ Tarek A. El Badawy (Corresponding author) \\ College of Business, Auburn University at Montgomery \\ Montgomery, AL 36117, USA \\ E-mail: tarek.elbadawy@aum.edu \\ Mariam M. Magdy \\ Telfer School of Management, University of Ottawa \\ Ottawa, ON, Canada K1N 6N5 \\ E-mail: mhuss059@uottawa.ca
}

Received: Sep. 22, 2019 Accepted: Oct. 25, 2019 Online published: Nov. 10, 2019

doi:10.5296/ijhrs.v9i4.15495 URL: https://doi.org/10.5296/ijhrs.v9i4.15495

\begin{abstract}
The resource-based view argues for the importance of creating a sustainable competitive advantage for organizations to survive and thrive. Through their people, organizations can create a strong diverse and immobile workforce. In this study, we explored the significance of strategic human resource management in Egyptian national organizations. We sought after the views of human resource managers on the activities organizations support to link their human resource management activities to long-term strategies and objectives. The qualitative semi-structured interviews highlighted common activities among the visited organizations. The findings demonstrated that strategic human resource management is still in its infancy stage. Egyptian organizations are losing dynamism because of the poor management of their
\end{abstract}


people.

Keywords: strategic human resources, Egypt, qualitative study, organizational performance

\section{Introduction}

The scientific endeavour to study the relationship between strategic human resource management (SHRM) and organizational performance has been extensive and supportive of the positive relationship between SHRM and organizational performance (Mitchell, Obeidat, and Bray, 2013; Posthuma, Campion, Masimova and Campion, 2013). In recent researches, SHRM is divided into content and process. Whereby content is described as all the HR activities organizations execute to hire, retain and develop the right types of employees who would fulfill the strategic goals of the organization. Process is concerned with the approach organizations use to communicate their HR activities to the employees in a correct and efficient manner (Katou, Budhwar and Patel, 2014).

Many of the studies were quantitative in nature, examining the perceptions of employees of SHRM and the influence of SHRM on organizational financial performance (Katou et al., 2014). We believe that the literature lacks enough qualitative studies that clearly reflect the human view on the SHRM activities. In addition, to our knowledge, no studies that tackle the same issues were found on Egypt or countries in the Middle East which are currently overwhelmed by many economic and political challenges and crises. The research question this study was: How does SHRM advance the organizational performance as viewed by HR managers working in national private organizations in Egypt?

In the attempt to enlarge the role of human resources in the organization, SHRM emerged as the connecting link between human resource management and the organization's goals and objectives (Delery, 1998). SHRM emphasizes the role of people in improving organizational performance and fostering innovation and flexibility (Fratricova and Rudy, 2015). Typically, strategic management is concerned with sustainability and long-term performance. Hence, with SHRM, the trending topics include teamwork facilitation, communication development, quality of workforce improvement, and talent development (Muduli, 2012).

A composite definition of SHRM would entail: A complete integration with the strategy and the strategic needs of the organization and cohered policies across different areas and hierarchies - which are accepted and implemented by line managers and employees as part of their everyday work. Accordingly, SHRM covers the foundations of policies, culture, values, and practices (Schuler, 1992). SHRM scholarship emerged around 30 years ago and has since evolved to include several streams of theory and empirical research (Jackson and Seo, 2010). Many authors have initiated and contributed hugely to the field including Jackson, Schuler and Jiang (2014), Wright and Boswell (2002), Becker and Huselid (1998), Wright and McMahan (1992), and Lengnick-Hall and Lengnick-Hall (1988).

\section{Theoretical Background}

The underlying theory that influenced this study was the resource-based theory (RBV). RBV helps explain the unidirectional relationship between SHRM and organizational performance. 
The most basic assumption is that SHRM activities will influence employee behaviors and attitudes and this will lead to the creation of an inimitable organizational resource that eventually creates positive changes in organizational performance (Mahoney, 2005).

SHRM is influenced by six themes - formulation of contingency perspectives and fit, shifting from a focus on the management of people to the creation of strategic contributions, elaboration of HR system components and structure, expansion of the SHRM scope, HR execution and evaluation of outcome (Lengnick-Hall, Lengnick-Hall, Andrade and Drake, 2009).

Formulating contingency perspectives and fit argues for creating a sustainable competitive advantage through organizational flexibility (in resources and coordination) and fit (internal and external). And the notion of HR contingencies has evolved from only making specific choices to accommodating special conditions to maintaining versatility by cultivating a repertoire from which to choose from to adjust to the shifting conditions (Lengnick-Hall et al., 2009).

Shifting from a focus on managing people to creating strategic contributions highlights the significance of human capital contributions, strategic capabilities, and an organization's competitive performance. Elaboration of HR system components and structure and Expansion of the SHRM scope focus on the elements and structure of the HR systems. HR policies and practices are too complex and interdependent that they should be examined as subsystems or bundles. This has led organizations and researchers to exert efforts to unpack HR systems into elements that could be examined in greater detail and subsequently blended into unique configurations. It became clear to many researchers that organizations rarely have a single HR system that covers all employees. As a matter of fact, most organizations have at least two systems (e.g., managerial and hourly).

Execution and evaluation of outcomes are concerned with developing valid measurements of the SHRM activities. Efforts to determine what to measure and how to measure it became the center of focus for researchers aiming to validate the role of SHRM in improving organizational performance. SHRM is implemented when the HR function is vertically aligned with the mission and objectives of the organization and integrated horizontally with other organizational functions. In sum, SHRM encompasses the integration of all human resource practices and the adherence to the broad goals of the organization and the quick responsiveness to the external environment (Ojo, 2011). SHRM is repeatedly proven to have direct and positive effects on financial and operational performance beside the employee relations' climate (Ratna and Singh, 2013).

\section{SHRM and Organizational Performance}

The interaction between SHRM and organizational performance is often investigated directly as well as indirectly through the many moderators and mediators which researchers hypothesize their influence on the strength and direction of the relationship. Some studies suggested that specific HR practices lead to the gain of a competitive advantage and subsequently the overall organizational performance is improved. These practices are titled 
"best practices" and "high performance work systems (HPWS)" and "high-involvement practices" and "high commitment practices" (Darwish and Singh, 2010). But there is a lack of agreement between researchers with respect to what these specific practices are and how many they should be.

Another team of researchers argue that HR practices influence some other variables. And these variables impact organizational performance down the road. This stream of research is still considered a black box with potential for further future investigations.

The RBV approach focuses on organizational competencies and the role of SHRM in the development of these competencies. According to the RBV, rare, valuable, inimitable, and non-substitutable resources can provide sustainable competitive advantage for organizations. HRM practices and policies that meet these criteria provide sustainability and enhance the performance of the organization (Gurbuz and Mert, 2011). Hence, our research question was: How does SHRM advance the organizational performance as viewed by HR managers working in national private organizations in Egypt?

\section{Methods}

We deemed the qualitative approach in collecting data and analyzing them suitable for the research question addressed in this paper. Interviewing participants provided the opportunity to collect in-depth information from the perspective of the executives. Content analysis of the interview transcripts helped in exploring potential answers with respect to how SHRM affect organizational performance and how managers assess the effectiveness of their SHRM practices.

\subsection{Interviewees}

Our participants were chosen with the purposive sampling technique. Ten HR managers working in national private Egyptian organizations were interviewed. They were either $H R$ Department Heads leading the HR department or HR managers working within the HR department and under the supervision of the HR Department Head. In the selected organizations, these positions were held by the most knowledgeable employees about all the processes planned and implemented inside the organization. Interviewees were from different organizations operating in several sectors. Because our efforts were focused on understanding the nature of SHRM in these organizations, socio-demographic factors were not considered intervening variables in our study.

\subsection{Procedures}

The selected interviewees were asked to sit for a one-hour interview. Invitations to participate were sent through electronic mail. When the participants replied with their interest in the study, the consent form with information about the study, the interview and the researchers were sent. The interview date and time were scheduled. The durations of the interviews ranged from thirty minutes to fifty-five minutes.

The interviews were semi-structured with four main guiding questions. Semi-structural interviews provided us with the opportunity to probe for additional information and to clarify any confusing answers. The interview had four main questions. They were: 1 . How does your 
organization view HRM practices in relation to its strategy? 2. How does the organization link the HRM practices to its strategy? 3. What are the reasons for integrating SHRM into the organization's operations? 4. How do these practices influence the organizational performance?

At the beginning of each interview, we asked whether the interviewee had any questions or concerns. All interviews were audio recorded and later transcribed. Any names and identifying information were removed to ensure anonymity.

\subsection{Data Analysis}

We analysed the full transcripts of the interviews manually. We analyzed the interviews in the spirit of Charmaz's (2006) approach to coding. The first cycle of reading resulted in the identification and grouping of important statements that reflect general themes (initial coding). The second cycle of data analysis involved grouping the general themes into higher order categories (focused coding). The second cycle of data analysis also helped in reducing the amount of data and producing conceptual themes that helped in answering the research question. As more interviews were conducted, we added new codes and adjusted the already identified codes. One review of all codes was conducted to ensure accuracy.

\section{Results}

Coding interviews resulted in the construction of several initial codes that were grouped under focused codes. All codes were generated inductively. In the following paragraphs, we will explain every focused code and its sub-codes.

Our interviewees identified specific HR functions and roles and corporate strategies which were viewed as the main pillars of SHRM. Our interviewees believed they influence organizational performance down the road. Seven SHRM enablers were identified from our analysis - organizational culture, HR practices, calibers' qualifications and skills, organizational development, employee's motivation and retention, organizational values and organizational corporate planning and management.

Our interviewees viewed their organizations strategically in terms of organizational development. Organizational development is reflected in continuous improvement of performance and the ability to survive in a risky and uncertain business environment. The interviews focused on HR strategies and organizational culture as two main pillars of development.

\subsection{Technical and Soft Skills'Training}

Interviewees agreed on the importance of training for organizational development and the achievement of long-term goals. Trainings are provided by a mixture of internal and external instructors. Trainings covered technical knowledge and personal skills. Several managers reflected on job rotation as their preferable learning tool.

Succession planning supports promoting from within the organization which helps in retaining the exceptional employees whom would feel appreciated. Internal promotions also 
achieve a lasting job satisfaction for the employees. Interviewees believed that succession planning will make their organizations employers of choice. It creates a strong sense of engagement for the employees, builds a strong culture and attracts the right talent needed for future vacancies.

\subsection{Flexible Systems}

As mentioned by our first interviewee, achievement of goals is based on "attracting the right talent, building the right and strong culture and raising the level of employee engagement". One of the main criteria employees care about nowadays when accepting a job offer is the flexibility. Having children and long-distance commuting are two main reasons why employees value flexible working hours and the ability to work from home. As stated by the third interviewee:

Engaged employees are loyal to their organizations which will have low turnover rates. Engaged employees are continuously developing and continuously improving themselves. Their performance and productivity are very high. This is reflected in their satisfaction surveys.

In addition, HR managers discussed the importance of achieving equity between all employees. This is mainly related to all HR operations where bias and discrimination are discouraged.

\subsection{Innovation}

With innovation, interviewees were focused on designing recruitment, training and development processes differently. The HR managers constantly seek innovation for three reasons: Reaching the right people, and minimizing costs, and penetrating their markets with new and demanded products.

\subsection{Communication}

The HR managers highlighted the importance of having an employee whose role is focused on facilitating communications. These employees are relations personnel managers. They are available to respond to employees' questions and they receive all problems and complaints and work on solving them.

\subsection{Organizational Development}

Organizational development was a common theme among our interviewees. Their view on development was reflected in: The creation of a development plan that is set by the HR "as a business partner" and communicated to the whole organization. The mid and end-of-year evaluations of the employees help them adjust their performances and affect the compensation and benefits functions.

Interestingly, in our sample, all interviewees agreed that they don't have, or have a very vague, long-term strategy for their organizations. They perform in murky water where they don't see a clear link between the strategic HR activities and the organizational performance. But, they "hope" the link is there. All interviewees agreed that the main output is the 
employee performance which is measured against KPIs set by the HR departments in every organization.

\section{Discussion}

The aim of this qualitative study was to explore the "black box" of strategic human resource management from the point of view of HR managers working in national private Egyptian organizations. We were also interested in understanding whether HR managers see a direct effect for SHRM on organizational performance. The analysis of the interviews revealed several interesting functions that HR managers believe influence organizational performance.

The training and development functions relate to retaining the good employees as they get motivated to stay for the company. It relates to innovation since employees get to learn how to be creative and innovative in their work. Finally, it relates to developing a strong sense of engagement in employees. It is often explained by the fact that employees get motivated and highly satisfied with the added value they receive from the training sessions offered to them within their organizations. It is also related to striving for efficiency because organizations tend to offer training sessions that help employees reduce waste in time and resources.

The recruitment and selection of employees relate to the strategy of growth within an organization because, in most cases, organizations that aim for growth would be hiring more people whom will contribute to developing the organization and achieving its goals. Recruitment also relates to building a strong culture by hiring the right people who are fit with the organization's culture.

The Organizational Development function relates to the strategy of creating internal communications. It relates to retaining the good employees. It is also concerned with the innovation that will help the organization continuously grow in addition to achieving a lasting satisfaction. It is also related to developing the talented people who will develop the organization as well. Organizational development makes the workplace an employer of choice. Our interviewees believed that having a full-fledged SHRM system within the organization will help in developing talented people and delivering high quality work.

\section{Limitations}

Two main obstacles were faced due to the nature of the organizations we visited. First, the concept of SHRM was relatively new to some of the managers we interviewed. This made their answers more general and sometimes, the SHRM-organizational performance link was difficult to comprehend. Second, the confidentiality of some data related to processes invented by the organizations and other internal functions made the process of gathering the information needed challenging.

\section{Future Research Recommendations}

Katou et al. (2014) argued that the content and the methods of planning and executing SHRM are complementary and essential to improving organizational performance. Hence, a multi-stage study that explores how structures of the SHRM are planned and executed would be of high value. 
The views of employees were not sought after in this study. Learning the views of both managers and employees is important to identify gaps in communications. As part of the SHRM process, communications may get distorted. Although managers may have the best intentions, their employees may receive wrong messages, understand the message differently, or there could be a lack of communication. All these obstacles lead to poor organizational performance.

The study was on the micro-level, seeking reflections of HR managers. Investigating both the micro and macro levels are important to further validate the contribution of SHRM in the improvement of organizational performance.

Understanding the real contribution of SHRM to the improvement of organizational performance remains a lucrative gap for future investigation. Moreover, the argument that the alleged relationship is significantly weak is corrected through investigating potential moderators and mediators (Mitchell et al., 2013).

\section{Practical Implications}

This study shed the light on many shortcomings happening in the Egyptian organizations. First, there is the lack of understanding and appreciation of the strategic role of HR and HR professionals. Second, there is a lack of a formal HR high-performing systems with clearly defined content and process. Third, HR managers are unable to have a line of sight regarding the role of SHRM in achieving organizational long-term goals.

We believe that in highly unstable environments, focusing on the humane aspects should be the highest priority for managers. This shall improve communication, motivation and nurture a positive environment. Initiatives include: Training employees to develop their skills and knowledge; educating employees about the social capital and facilitating communications between colleagues inside and outside the organization to develop relationships.

\section{References}

Becker, B. E., \& Huselid, M. A. (1998). High performance work systems and firm performance: A synthesis of research and managerial implications. Research in Personnel and Human Resources Management, 16, 53-101.

Charmaz, K. (2006). Constructing grounded theory: A practical guide through qualitative analysis. Thousand Oaks: Sage, pp. 42-71.

Darwish, T., \& Singh, S. (2010). SHRM and organizational performance: Issues and challenges. Proceedings of the European Conference on Management, Leadership \& Governance, 93-100.

Delery, J. E. (1998). Issues of fit in strategic human resource management: Implications for research. Human Resource Management Review, 8(3), 289-309. https://doi.org/10.1016/S1053-4822(98)90006-7

Fratricova, J., \& Rudy, J. (2015). Get strategic human resource management really strategic: Strategic HRM in practice. International Journal of Management Cases, 17(4), 149-155. 


\section{Mll Macrothink}

International Journal of Human Resource Studies

ISSN 2162-3058

2019, Vol. 9, No. 4

Gurbuz, S., \& Mert, I. S. (2011). Impact of the strategic human resource management or organizational performance: Evidence from Turkey. The International Journal of Human Resource Management, 22(8), 1803-1822. https://doi.org/10.1080/09585192.2011.565669

Jackson, S. E., \& Seo, J. (2010). The greening of Strategic HRM scholarship. Organization Management Journal, 7, 278-290. https://doi.org/10.1057/omj.2010.37

Jackson, S. E., Schuler, R. S., \& Jiang, K. (2014). An aspirational framework for strategic human resource management. The Academy of Management Annals, 8(1), 1-56. https://doi.org/10.5465/19416520.2014.872335

Katou, A., Budhwar, P. S., \& Patel, C. (2014). Content vs. process in the HRM-performance relationship: An empirical examination. Human Resource Management, 53(4), 527-544. https://doi.org/10.1002/hrm.21606

Lengnick-Hall, C. A., \& Lengnick-Hall, M. L. (1988). Strategic human resources management: A review of the literature and a proposed typology. The Academy of Management Review, 13(3), 454-470. https://doi.org/10.5465/amr.1988.4306978

Lengnick-Hall, M. L., Lengnick-Hall, C. A., Andrade, L. S., \& Drake, B. (2009). Strategic human resource management: The evolution of the field. Human Resource Management Review, 19(2), 64-85. https://doi.org/10.1016/j.hrmr.2009.01.002

Mahoney, J. T. (2005), Economic foundations of strategy. Thousand Oaks, CA: Sage Publications.

Mitchell, R., Obeidat, S., \& Bray, M. (2013). The effect of strategic human resource management on organizational performance: The mediating role of high-performance human resource practices. Human Resource Management, 52(6), 899-921. https://doi.org/10.1002/hrm.21587

Muduli, A. (2012). Business Strategy, SHRM, HR Outcome and Organizational performance: Evidence from an Indian industry. Global Management Journal, 1/2, 111-125.

Ojo, O. (2011). Impact of strategic human resource practice on corporate performance in selected Nigerian banks. EGE Academic Review, 11(3), 339-347. https://doi.org/10.21121/eab.2011319552

Posthuma, R. A., Campion, M. C., Malika, M., \& Campion, M. A. (2013). A high-performance work practices taxonomy: Integrating the literature and directing future research. Journal of Management, 39(5), 1184-1220. https://doi.org/10.1177/0149206313478184

Ratna, R., \& Singh, P. P. (2013). SHRM practices and employee satisfaction: Study and relationship. Amity Management Review, 3(1), 75-83.

Schuler, R. S. (1992). Strategic Human Resource Management: Linking the people with the strategic needs of the business. Organizational Dynamics, 21(1), 18-32. https://doi.org/10.1016/0090-2616(92)90083-Y 


\section{Macrothink}

International Journal of Human Resource Studies

ISSN 2162-3058 2019, Vol. 9, No. 4

Wright, P. M., \& Boswell, W. R. (2002). Desegregating HRM: A review and synthesis of micro and macro human resource management research. Journal of management, 28(3), 247-276. https://doi.org/10.1177/014920630202800302

Wright, P. M., \& McMahan, G. C. (1992). Theoretical perspectives for strategic human resource management. Journal of management, 18(2), 295-320. https://doi.org/10.1177/014920639201800205

\section{Copyright Disclaimer}

Copyright for this article is retained by the author(s), with first publication rights granted to the journal.

This is an open-access article distributed under the terms and conditions of the Creative Commons Attribution license (http://creativecommons.org/licenses/by/4.0/). 